\title{
Determination of Elements Profile of Some Wild Edible Plants
}

\author{
Ali Aberoumand • S. S. Deokule
}

Received: 8 April 2008 / Accepted: 16 May 2008 / Published online: 8 July 2008

(C) The Author(s) 2008

\begin{abstract}
Fruits and leafy vegetables are believed to occupy a modest place as a source of trace elements due to their high water content. Most of nutrient requirements can be met by increasing the consumption of fruits and vegetables to 5-13 servings/day. In addition to meeting nutrient intake levels, greater consumption of fruits and vegetables is associated with reduced risk of cardiovascular disease, stroke, and cancers of the mouth, pharynx, esophagus, lungs, stomach, and colon. Therefore, vegetable and fruit consumption prevents sickness in population. Results in this research showed that Portulaca oleracia Linn. contains high value of macroelements such as sodium $(7.17 \mathrm{mg} / \mathrm{g})$, potassium $(14.71 \mathrm{mg} / \mathrm{g})$, and calcium $(18.71 \mathrm{mg} / \mathrm{g})$, and high ash value in comparison with other plants. Also, Eulophia ochreata Lindl. has maximum micro-elements such as iron $(5.04 \mathrm{mg} / \mathrm{g})$ and zinc $(3.83 \mathrm{mg} / \mathrm{g})$ in comparison with other plants in this study. Therefore, we can conclude that $P$. oleracia Linn. has high nutritional values from the viewpoint of macro-elements such as sodium, potassium, and calcium; and because E. ochreata Lindl. has micro-elements in maximum amounts such as iron and zinc in comparison with other edible plants, it has high
\end{abstract}

\footnotetext{
A. Aberoumand

Department of Food Science,

Natural Resources College of Behbahan,

Shehid Chamran University of Ahvaz,

Ahvaz, Iran

S. S. Deokule

Department of Botany, Pune University,

Pune, India

A. Aberoumand $(\bowtie)$

No:22, Alley $2 \mathrm{Ab}$ va bargh, Zolfeghari Street,

Behbehan City, Khuzestan Province, Iran

e-mail: Aberoumand38@yahoo.com

nutritional value from the viewpoint of the above trace (micro) elements. Momordica dioicia Roxb. or Cordia myxa Roxb have the lowest nutritional values because they have ash minimum values. $M$. dioicia Roxb. contains minimum values of sodium and calcium, but C. myxa Roxb. has zinc minimum value. Alocacia indica Sch., Asparagus officinalis DC., Chlorophytum comosum Linn., C. myxa Roxb., E. ochreata Lindl. have medium nutritional values.

Keywords Minerals $\cdot$ Portulaca oleracia . Eulophia ochreata $\cdot$ Nutritional Value

\section{Introduction}

Iron is an essential mineral and an important component of proteins involved in oxygen transport and metabolism. Iron is also an essential cofactor in the synthesis of neurotransmitters such as dopamine, norepinephrine, and serotonin. About $15 \%$ of the body's iron is stored for future needs and mobilized when dietary intake is inadequate.

Sources of non-heme iron, which is not absorbed as well as heme iron, include beans, lentils, flours, cereals, and grain products. Other sources of iron include dried fruit, peas, asparagus, leafy greens, strawberries, and nuts (Black 2004).

Zinc is necessary for the functioning of over 300 different enzymes and plays a vital role in an enormous number of biological processes. Zinc is a cofactor for the antioxidant enzyme super oxide dismutase (SOD) and is in a number of enzymatic reactions involved in carbohydrate and protein metabolism.

Based on available scientific evidence, zinc may be efficacious in the treatment of (childhood) malnutrition, acne vulgaris, peptic ulcers, leg ulcers, infertility, Wilson's disease, herpes, and taste or smell disorders. Zinc has also gained 
Fig. 1 Amounts of macro elements of edible plants

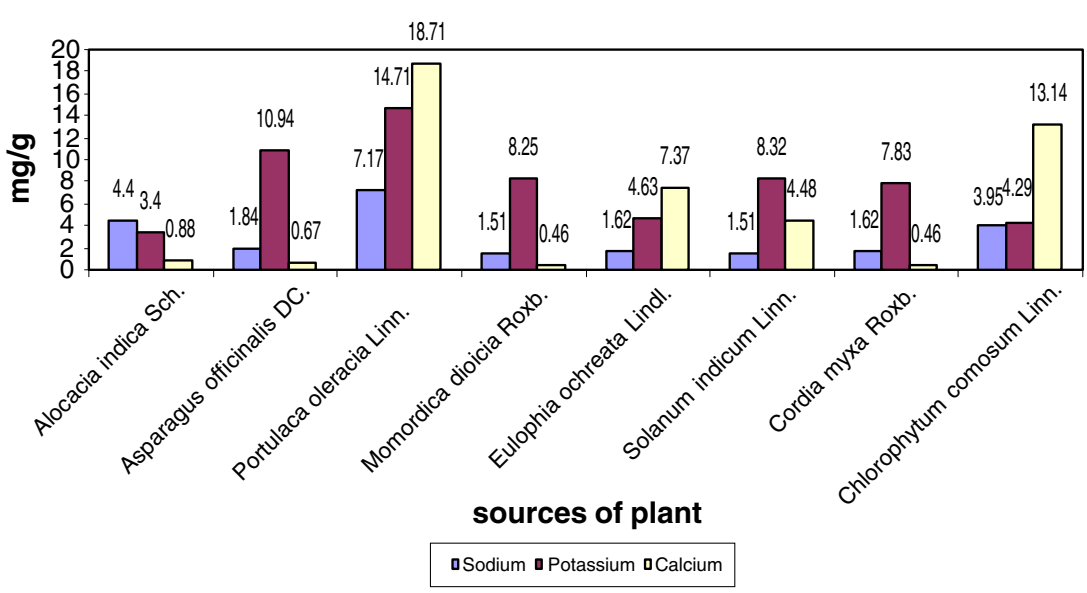

popularity for its use in prevention of the common cold (AlMaroof 2006).

Leafy vegetables hold an important place in well-balanced diets. The idea itself of a well-balanced diet changed in recent years and lesser amounts of red meat and more vegetable and fruits are advised (Ames and Gold 1996; Lucarini and Canali 1999; Kratzer and Vohra 1986). On the other hand, with few exceptions, fruits and leafy vegetables are believed to occupy a modest place as a source of trace elements due to their high water content (Gibson 1994).

Nutritional information is used increasingly by public agencies and agricultural industries to promote fresh produce. Consumers are looking for variety in their diets, and are aware of the health benefits of fresh fruits and vegetables. Of special interest are food sources rich in antioxidant vitamins (vitamins $\mathrm{C}, \mathrm{A}$, and $\mathrm{E})$, calcium $(\mathrm{Ca})$, magnesium $(\mathrm{Mg})$, and potassium
(K). The 2005 Dietary Guidelines Advisory Committee recommended increasing the dietary intake of vitamins $\mathrm{A}, \mathrm{C}$, and $\mathrm{E}, \mathrm{Ca}, \mathrm{Mg}, \mathrm{K}$, and fiber (USDA/HHS 2004). Most of these nutrient requirements can be met by increasing the consumption of fruits and vegetables to 5-13 servings/day (USDA/HHS 2004). In addition to meeting nutrient intake levels, greater consumption of fruits and vegetables is associated with reduced risk of cardiovascular disease, stroke, and cancers of the mouth, pharynx, esophagus, lungs, stomach, and colon (Bazzano 2002; Gillman 1995; Joshipura 2001; Riboli and Norat 2003).

The present work aimed at determining the total of five nutritionally important minerals (calcium, iron, zinc, sodium, and potassium) in leafy green vegetables widely consumed in Iran and India. The objective of the present work was to examine the variability in the mineral content during the course of a year in order to be able to reach an average value
Fig. 2 Amounts of micro elements of edible plants

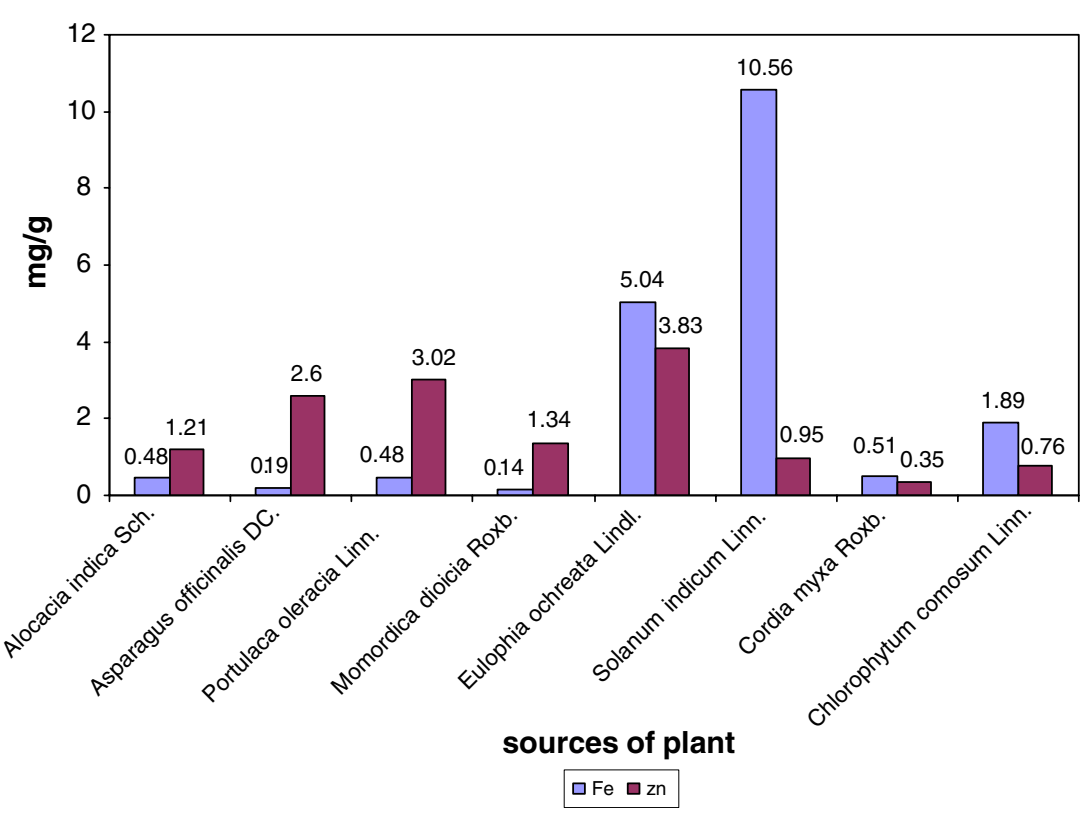


Table 1 Amounts of macro elements and ash of eight edible plants obtained from Iran and India

\begin{tabular}{lcccc}
\hline Samples & Total ash (\%) & $\begin{array}{l}\text { Sodium (Na) } \\
\mathrm{mg} / \mathrm{g}\end{array}$ & $\begin{array}{l}\text { Potassium(K) } \\
\mathrm{mg} / \mathrm{g}\end{array}$ & $\begin{array}{l}\text { Calcium(Ca) } \\
\mathrm{mg} / \mathrm{g}\end{array}$ \\
\hline Alocacia indica Sch. & 7.3 & 4.4 & 3.4 & 0.88 \\
Asparagus officinalis DC. & 10.7 & 1.84 & 10.94 & 0.67 \\
Portulaca oleracia Linn. & 22.6 & 7.17 & 14.71 & 18.71 \\
Momordica dioicia Roxb. & 6.7 & 1.51 & 8.25 & 0.46 \\
Eulophia ochreata Lindl. & 9.1 & 1.62 & 4.63 & 7.37 \\
Solanum indicum Linn. & 11.0 & 1.51 & 8.32 & 4.48 \\
Cordia myxa Roxb. & 6.7 & 1.62 & 7.83 & 0.46 \\
Chlorophytum comosum Linn. & 10.38 & 3.95 & 4.29 & 13.14 \\
\hline
\end{tabular}

and as well as the probable variation to be expected for the minerals in the studied vegetables.

\section{Materials and Methods}

\section{Collection of Samples}

Eight different types of fruits and vegetables Alocacia indica Sch (common name polly dwarf), Asparagus officinalis DC (common name asparagus, local name marchobeh), Chlorophytum comosum Linn. (common name spider plant, local name sejafi), Cordia myxa Roxb. (common name large sebesten, local name sepestan), Eulophia ochreata Lindl. (common name, wild coco), Momordica dioicia Roxb. (common name wild balsam apple), Portulaca oleracia Linn. (common name moss rose, local name parpin) and Solanum indicum Linn. (common name egg plant, local name angirak) were purchased/collected from various localities of Maharashtra (India) and Iran. Five wild edible plants were collected from Iran, viz A. officinalis, C. comosum, $C$. myxa, $P$. oleracia and $S$. indicum in October 2006 and April 2007. Efforts were made to collect these plants in flowering and fruiting conditions for the correct botanical identification. Healthy and disease-free edible plant part/s selected from each variety of fruit and vegetables were collected to assess total phenolic contents.

Table 2 Amounts of trace elements and ash of eight edible plants obtained from Iran and India

\begin{tabular}{lccc}
\hline Samples & Total ash (\%) & Fe mg/g & Zn mg/g \\
\hline Alocacia indica Sch. & 7.3 & 0.48 & 1.21 \\
Asparagus officinalis DC. & 10.7 & 0.19 & 2.60 \\
Portulaca oleracia Linn. & 22.6 & 0.48 & 3.02 \\
Momordica dioicia Roxb. & 6.7 & 0.14 & 1.34 \\
Eulophia ochreata Lindl. & 9.1 & 5.04 & 3.83 \\
Solanum indicum Linn. & 11.0 & 10.56 & 0.95 \\
Cordia myxa Roxb. & 6.7 & 0.51 & 0.35 \\
Chlorophytum comosum Linn. & 10.38 & 1.89 & 0.76 \\
\hline
\end{tabular}

\section{Samples Preparation}

Fresh fruits and vegetables were cleaned with water and external moisture wiped out with a dry cloth. The edible portion of the individual fruits was separated and dried in a hot air oven at $50^{\circ} \mathrm{C}$ for $1 \mathrm{~h}$. The dried samples were then powdered in a blender for further study.

Some of the plants were dried under shade so as to prevent the decomposition of chemical compounds present in them.

\section{Determination of Minerals}

One gram of each of the samples were dry-ashed in a crucible in furnace at $550^{\circ} \mathrm{C}$ for about $7 \mathrm{~h}$. The ash was dissolved in $10 \mathrm{HCl}$ in a conical flask. The solution was filtered into a $100 \mathrm{ml}$ standard flask and made up to the mark with distilled water. The individual mineral element was measured from this solution, $\mathrm{Ca}$, Na, and $\mathrm{K}$ using the Flame Photometer (Jenway, U.K.) and Fe and $\mathrm{Zn}$ by Atomic Absorption Spectrophotometer (PerkinElmer, Analyst 200; AOAC 1984).

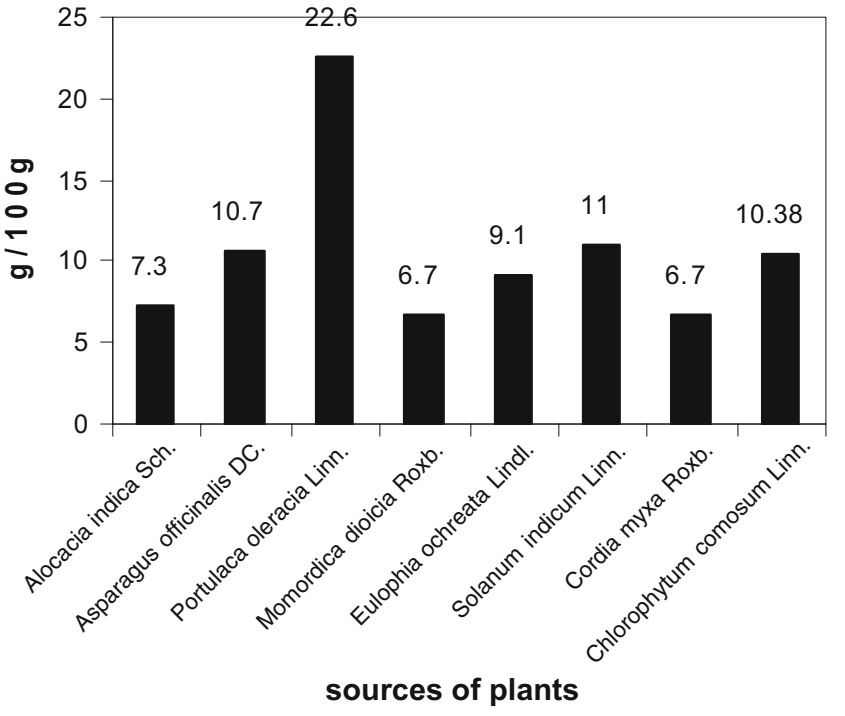

Fig. 3 Amounts of ash of edible plants 


\section{Results and Discussion}

The sodium value of $P$. oleracia Linn. was maximum and sodium values of $M$. dioicia Roxb. and $S$. indicum Linn. were minimum, while the sodium value of $A$. indica Sch. was medium (Fig. 1).

The potassium value of $P$. oleracia Linn. was maximum and potassium value of $A$. indica $\mathrm{Sch}$. was minimum, while the potassium value of C. myxa Roxb. was medium (Fig. 1).

The calcium value of $P$. oleracia Linn. was maximum and the calcium values of $M$. dioicia Roxb. and C. myxa Roxb. were minimum, while the calcium value of $E$. ochreata Lindl. was medium (Fig. 1).

The iron value of $E$. ochreata Lindl. was maximum and the iron value of $M$. dioicia Roxb. was minimum while the iron value of C. comosum Linn. was medium (Fig. 2).

The zinc value of $E$. ochreata Lindl. was maximum and the zinc value of $C$. myxa Roxb. was minimum while the zinc value of $A$. officinalis DC. was medium (Fig. 2).

It is observed that the macro-element values of $P$. oleracia Linn. were high, especially since it has high ash value in comparison with other edible plants; therefore, $P$. oleracia Linn. has high nutritional value. Also, since $E$. ochreata Lindl. has maximum micro-elements such as iron $(5.04 \mathrm{mg} / \mathrm{g})$ and zinc $(3.83 \mathrm{mg} / \mathrm{g})$ in comparison with other plants in this study, it has high nutritional value. Duke and Ayensu (1985) reports that the amounts of calcium, iron, sodium, and potassium in A. officinalis were $22 \mathrm{mg} / 100 \mathrm{~g}$, $1 \mathrm{mg} / 100 \mathrm{~g}, 2 \mathrm{mg} / 100 \mathrm{~g}, 278 \mathrm{mg} / 100 \mathrm{~g}$, respectively. They also reported the amounts of ash, calcium, iron, potassium, and sodium in P. oleracia to be $20 \mathrm{mg} / 100 \mathrm{~g}, 1,500 \mathrm{mg} /$ $100 \mathrm{~g}, 29 \mathrm{mg} / 100 \mathrm{~g}, 1,800 \mathrm{mg} / 100 \mathrm{~g}$ and $55 \mathrm{mg} / 100 \mathrm{~g}$ respectively. Parmar and Kaushal (1982) reports the amount of potassium, calcium, and iron to be $0.066 \mathrm{~g} / 100 \mathrm{~g}$, $0.062 \mathrm{~g} / 100 \mathrm{~g}, 0.005 \mathrm{~g} / 100 \mathrm{~g}$, respectively. Oboh et al (2004) reports the amount of zinc and calcium in S. indicum to be $3.4-5.7 \mathrm{mg} / \mathrm{kg}$ and $12-18.2 \mathrm{mg} / \mathrm{kg}$, respectively. Comparison of data with reported results showed that in the case of Portulaca, except the amount of potassium, all amounts of minerals in this study were shown to be more than the researchers' reported results. Also, this comparison showed that in the case of asparagus, all amounts of minerals in this study were shown to be more than the researchers' reported results, and in the case of Cordia, all amounts of minerals in this study were shown less than researchers' reported results (Tables 1 and 2 and Fig. 3).
Therefore, we can conclude $P$. oleracia Linn. has high nutritional value from the viewpoint of macro-elements such as sodium, potassium, and calcium. Because E. ochreata Lindl. has micro-elements in maximum amounts such as iron and zinc in comparison with other edible plants, it has high nutritional value from viewpoint of the above trace (micro) elements. M. dioicia Roxb. or C. myxa Roxb. have the minimum nutritional values, because they have ash minimum values. $M$. dioicia Roxb. has sodium and calcium minimum values, but $C$. myxa Roxb. has zinc minimum value. $A$. indica Sch., A. officinalis DC., C. comosum Linn., C. myxa Roxb., E. ochreata Lindl. have medium nutritional values.

Acknowledgments The authors are grateful to the Head Department of Botany University of Pune for providing necessary laboratory facilities and for encouragement. The first author is thankful to Head Department of Food Science Technology of Ramin Agricultural University of Iran.

Open Access This article is distributed under the terms of the Creative Commons Attribution Noncommercial License which permits any noncommercial use, distribution, and reproduction in any medium, provided the original author(s) and source are credited.

\section{References}

Al-Maroof K (2006) Serum zinc and iron levels in diabetic patients and effect of them supplementation on glycemic control of type 2 diabetics. Saudi Med J 27:344-350

Ames B, Gold LS (1996) Mom was right, at least about fruits and vegetables. Chem Heal Saf 3:17-21

Bazzano M (2002) Fruit and vegetable intake and risk of cardiovascular disease in US adults: the first National Health and Nutrition Examination Survey Epidemiologic follow-up study. Am J Clin Nutr 76:93-99

Black R (2004) Iron and zinc supplementation promote motor development and exploratory behavior among Bangladeshi infants. Am J Clin Nutr 80:903-910

Gibson RS (1994) Zinc nutrition in developing countries. Nutr Res Rev 7:151-173

Gillman S (1995) Protective effect of fruits and vegetables on development of stroke in men. J Am Med Assoc 273:1113-1117

Joshipura H (2001) The effect of fruit and vegetable intake on risk for coronary heart disease. Ann Intern Med 134:1106-1114

Kratzer F, Vohra P (1986) The effect of diet on plasma lipids, lipoprotein, and coronary heart disease. J Am Diet Assoc 88:1373-1411

Lucarini S Canali R (1996) National Research Council. Carcinogens and anti carcinogens in the human diet. National Academy Press, Washington, pp 221-232

Riboli A (2003) Epidemiologic evidence of the protective effect of fruit and vegetables on cancer risk. Am J Clin Nutr 78:559-569 